\title{
Comparing trends in mortality from cardiovascular disease and cancer in the United Kingdom, 1983-2013: joinpoint regression analysis
}

\author{
Lauren Wilson, Prachi Bhatnagar and Nick Townsend*
}

\begin{abstract}
Background: We aimed to study the time trends underlying a change from cardiovascular disease (CVD) to cancer as the most common cause of age-standardized mortality in the UK between 1983 and 2013.

Methods: A retrospective trend analysis of the World Health Organization mortality database for mortality from all cancers, all CVDs, and their three most common types, by sex and age. Age-standardized mortality rates were adjusted to the 2013 European Standard Population and analyzed using joinpoint regression analysis for annual percent changes.

Results: The difference in mortality rate between total CVD and cancer narrowed over the study period as agestandardized mortality from CVD decreased more steeply than cancer in both sexes. We observed higher overall rates for both diseases in men compared to women, with high mortality rates from ischemic heart disease and lung cancer in men. Joinpoint regression analysis indicated that trends of decreasing rates of CVD have increased over time while decreasing trends in cancer mortality rates have slowed down since the 1990s. The lowest improvements in mortality rates were for cancer in those over 75 years of age and lung cancer in women.
\end{abstract}

Conclusions: In 2011, the age-standardized mortality rate for cancer exceeded that of CVD in both sexes in the UK. These changing trends in mortality may support evidence for changes in policy and resource allocation in the UK.

Keywords: Cancer, Cardiovascular disease, Epidemiology, Mortality, Joinpoint regression analysis

\section{Background}

In 2013, cardiovascular disease (CVD) was the most common cause of mortality in Europe, Asia, and the Americas, with the majority of CVD deaths occurring due to ischemic heart disease (IHD) [1]. Cancer was the second most common cause of death in these regions, with lung cancer the most common type. CVD had been the most common cause of death in the UK since the middle of the twentieth century but was overtaken by cancer in 2011 for men [2]. Of the 570,341 deaths in the United Kingdom (UK) in 2014, 29.4\% were due to

\footnotetext{
*Correspondence: nicholas.townsend@dph.ox.ac.uk

Nuffield Department of Public Health, British Heart Foundation Centre on

Population Approaches for Non-Communicable Disease Prevention,

University of Oxford, Old Road Campus, Oxford OX3 7LF, UK
}

cancer and 27.1\% were due to CVD, with both diseases still representing major public health burdens.

Recent publications suggest a change from CVD to cancer as the most common cause of death in the UK and some other European countries [3, 4]. This warrants a comparative analysis as both diseases have been decreasing in the UK since the 1980s. In particular, IHD mortality in the UK had one of the largest decreases in Europe [5]. Recent articles have suggested that this decrease is not equal across population groups, with exceptions such as a plateau in decreasing CVD mortality at younger ages $[3,6]$ and a rise in female but not male lung cancer mortality [4].

It is unclear how underlying sex-, age-, and diseasetype-specific trends have contributed toward a shift from CVD to cancer as the most common cause of death and 
when such changes in mortality rates occurred. We found only one study from Portugal that compared cancer and CVD mortality within the same analysis for a European country [7]. Although their study considered trends in age-standardized mortality rates and years of life lost by age group and sex from 1980 to 2010, their breakdown was limited to total CVD and total cancer rates. The analysis of disease types is important due to the differences in etiology between CVD and cancer types [8]. For this reason, our analysis includes mortality trends in IHD and stroke that account for $71 \%$ of UK CVD deaths, and the four leading causes of cancer mortality (lung, colon, breast, and prostate) which account for $45 \%$ of UK cancer mortality. We aimed to compare observational trends in CVD and cancer mortality by sex, age, and disease types from 1983 to 2013, to provide evidence for recent UK mortality trends.

\section{Data and methods Mortality data}

We obtained the number and cause of medically certified deaths for the United Kingdom from the World Health Organization (WHO) global mortality database online (updated November 2015). Data were available for all calendar years from 1983 to 2013, except the year 2000 , grouped by five-year age groups and sex. Data between the years 1983 and 1999 used the International Classification of Diseases (ICD) revision 9 up to 85+ years of age. Years 2001 to 2013 used the ICD 10th revision up to age $95+$ years of age. We chose disease categories based on the leading causes of death in the UK and ICD - 10 categories as utilized by WHO and the Global Burden of Disease study [9, 10]. Data for total deaths were obtained for Chapter 2 (neoplasms) and Chapter 9 (circulatory system) of the ICD and their three most common disease types in the UK (Table 1). Concordant coding was used to match transition between ICD revisions [10]. We included benign tumors in the broad analysis due to coding reassignments from non-malignant to malignant, and vice versa, from the revision of ICD-9 to ICD-10 in the UK [9]. We excluded benign tumors from typespecific analysis due to lack of accessible data before 2001. Western Europe refers to the definition used by the Global Burden of Disease study.

\section{Population data}

We obtained midyear population estimates for the UK from the Office for National Statistics (ONS) website. We used these in preference to WHO data as this source provided the most up-to-date population estimates from the 2011 census. Data were available for each calendar year in five-year age groups up to $85+$ years until 2000, and up to $90+$ years thereafter.

\section{Age-standardization}

Mortality and population data were organized into fiveyear age groups, up to $85+$ years, to correspond with age categories used in the 2013 European Standard Population (ESP) and those provided in mortality and population data. We calculated age-standardized rates per 100,000 with 95\% confidence intervals (CI) for each study year (1983-2013) using the direct method, based on the 2013 ESP and age-specific crude rates. Microsoft Excel 2010 was used to calculate age-standardized rates by sex and age groups.

\section{Annual percentage change (APC)}

We used joinpoint regression to analyze trends in agestandardized CVD and cancer mortality rates. Analysis was performed by sex, 15-year age group, and disease type. Joinpoint analysis identifies the best fit for inflexion points ("joinpoints") at which there is a significant change in trends using a series of permutation tests,

Table 1 International Classification of Disease (ICD) by revision and years utilized in the UK, 1983-2013

\begin{tabular}{|c|c|c|c|}
\hline WHO ICD definition & Detailed ICD-10 2001-2013 & Detailed ICD-9 1998-1999 & ICD-9 basic tabulation 1983-1997 \\
\hline \multicolumn{4}{|l|}{ Neoplasms } \\
\hline Malignant & C00-C97 & $140-208$ & B08-B14 \\
\hline Benign, in situ, or unknown & D00-D48 & $210-239$ & B15-B17 \\
\hline Trachea, bronchus, lung & C33, C34 & 162 & B101 \\
\hline Colon, sigmoid, rectum, anus & C18-C21 & 153,154 & B093, B094 \\
\hline Breast (female) & $\mathrm{C} 50$ & 174 & B113 \\
\hline Prostate (male) & C61 & 185 & B124 \\
\hline Diseases of the circulatory system & $100-199$ & $390-459$ & B25-B30 \\
\hline $\begin{array}{l}\text { Ischemic heart diseases } \\
\text { Cerebrovascular diseases } \\
\text { Other cardiovascular \& heart disease }\end{array}$ & $\begin{array}{l}120-125 \\
160-169 \\
100,126-128,134-137 \\
144-151,170-199\end{array}$ & $\begin{array}{l}410-414 \\
430-438 \\
415-417,423-424, \\
426-429,440-448,451-459\end{array}$ & $\begin{array}{l}\text { B27 } \\
\text { B29 } \\
\text { B28, B30 }\end{array}$ \\
\hline
\end{tabular}

\footnotetext{
${ }^{a}$ Year 2000 data not available
} 
Table 2 Joinpoint analysis of age-standardized ${ }^{b}$ mortality rate from cancer and cardiovascular diseases (CVD) by sex

\begin{tabular}{|c|c|c|c|c|c|c|c|c|c|c|}
\hline & \multicolumn{2}{|c|}{ Absolute deaths (Rate per 100,000) } & \multicolumn{2}{|c|}{ Total study period ${ }^{c}$} & \multicolumn{2}{|l|}{ Period 1} & \multicolumn{2}{|l|}{ Period 2} & \multicolumn{2}{|l|}{ Period 3} \\
\hline & 1983 & 2013 & Average APC (\%) & $95 \% \mathrm{Cl}$ & Years & APC (\%) & Years & APC (\%) & Years & APC (\%) \\
\hline \multicolumn{11}{|l|}{ Cancer } \\
\hline Male & $80,553(464.9)$ & $87,511(350.9)$ & $-1.0^{\mathrm{a}}$ & $-1.1,-0.8$ & 1983-1991 & 0.0 & 1991-1997 & $-1.8^{\mathrm{a}}$ & 1997-2013 & $-1.2^{\mathrm{a}}$ \\
\hline Female & $71,265(277.3)$ & $78,331(242.7)$ & $-0.5^{\mathrm{a}}$ & $-0.6,-0.4$ & 1983-1989 & $0.7^{\mathrm{a}}$ & 1989-1997 & $-1.0^{\mathrm{a}}$ & 1997-2013 & $-0.7^{\mathrm{a}}$ \\
\hline \multicolumn{11}{|l|}{ CVD } \\
\hline Male & $158,944(1035.3)$ & 79,935 (334.3) & $-3.9^{\mathrm{a}}$ & $-4.0,-3.7$ & 1983-2001 & $-2.8^{\mathrm{a}}$ & 2001-2013 & $-5.4^{\mathrm{a}}$ & & \\
\hline Female & $164,349(665.8)$ & $79,860(227.9)$ & $-3.7^{\mathrm{a}}$ & $-3.8,-3.5$ & $1983-2003$ & $-2.7^{\mathrm{a}}$ & 2003-2013 & $-5.6^{\mathrm{a}}$ & & \\
\hline
\end{tabular}

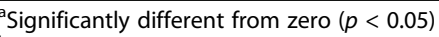

${ }^{\text {b }}$ Standardized to the 2013 European standard population by 5-year age groups

c Years 1983 to 2013

$A P C$, annual percentage change

with Bonferroni adjustment for multiple comparisons. In this study, joinpoint analysis was used to identify years (as the independent variable) at which significant changes in mortality rate occurred over the study period and the size of these changes (as the percentage change in rate per year). The use of a natural log-linear model enables the analysis of a constant percentage change in rate over time. We allowed up to four joinpoints utilizing a Monte Carlo permutation method and evaluated whether there was a difference from no change of each segment using a $p$-value of less than 0.05 as statistically significant. We computed joinpoints using the Joinpoint trend analysis software from the Surveillance Research Program of the National Cancer Institute Version 4.2.0.2 (Statistical Research and Applications Branch, National Cancer Institute, US).

\section{Results}

Of the 576,458 deaths in the UK in 2013, cancer was the recorded cause for 165,875 people and CVD was the recorded cause for 159,795 (Table 2). Between 1983 and 2013, age-standardized mortality rates for total CVDs and total cancers decreased; however, the decrease in cancer was much less steep in comparison to CVD (Fig.
1). Overall, total age-standardized CVD mortality decreased by $67 \%$ and total cancer mortality decreased by $18 \%$ over 30 years. The absolute number of deaths from cancer increased over the study period while the number of deaths from CVD decreased (Table 2).

The decreases in age-standardized mortality rates for cancer and CVD were similar when comparing rates between sexes, but rates were consistently higher in men than in women throughout the period (Fig. 1, Table 2). The ratio of age-standardized deaths from CVD to cancer in men changed from 2.2 in 1983 to 0.95 in 2013. In women, this ratio changed from 2.4 in 1983 to 0.94 in 2013. For absolute deaths, cancer overtook CVD as the most common cause of death for men in 2011, and women in 2014 [11], but by age-standardized mortality, rates of cancer surpassed CVD in both sexes in 2011.

Joinpoint regression analysis showed one joinpoint for age-standardized CVD mortality trends in men and women, indicating two significant periods of decreasing mortality rates (Table 2). The steepest CVD decreases were in the second period, with a significant decrease of $5.4 \%$ per year in men and $5.6 \%$ in women. Trends in age-standardized cancer mortality showed two joinpoints for both sexes, with significant decreases in the second

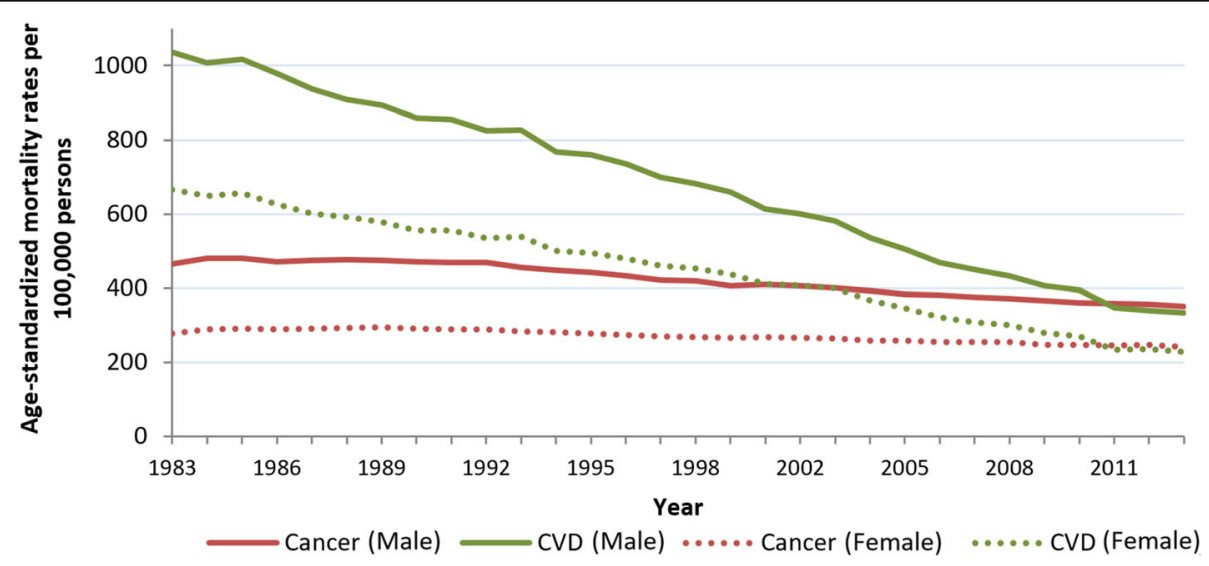

Fig. 1 Age-standardized mortality trends for cancer (including benign) and cardiovascular diseases in the UK. Legend: Years 1983 to 2013 


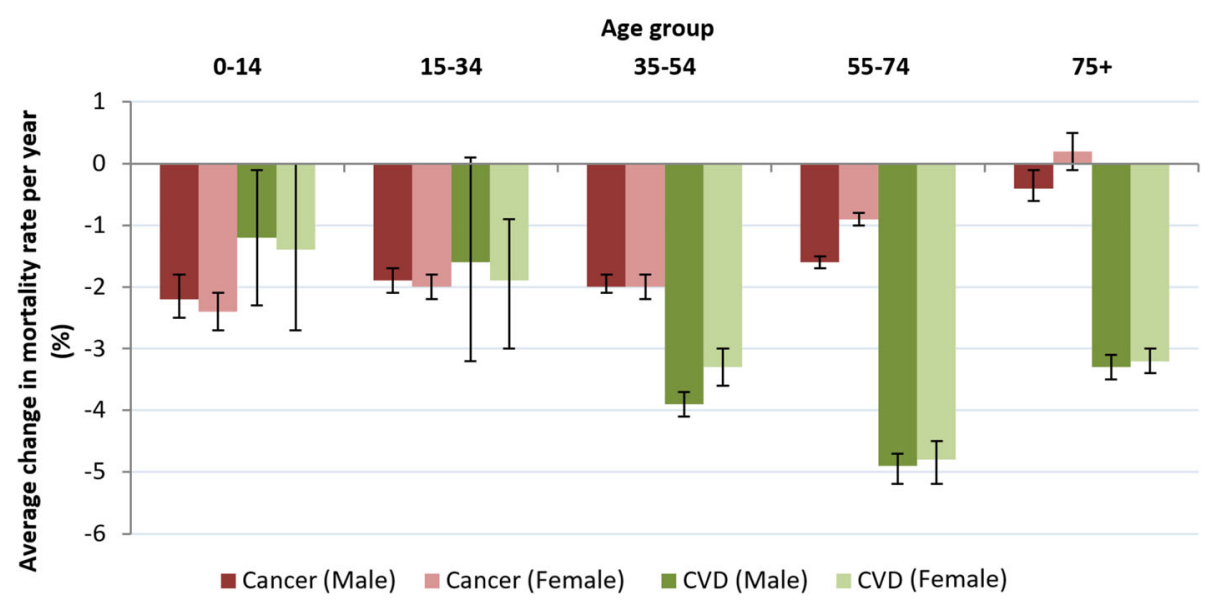

Fig. 2 Average change in age-standardized mortality rate per year as a percentage. Legend: Years 1983 to 2013. Error bars as 95\% confidence intervals

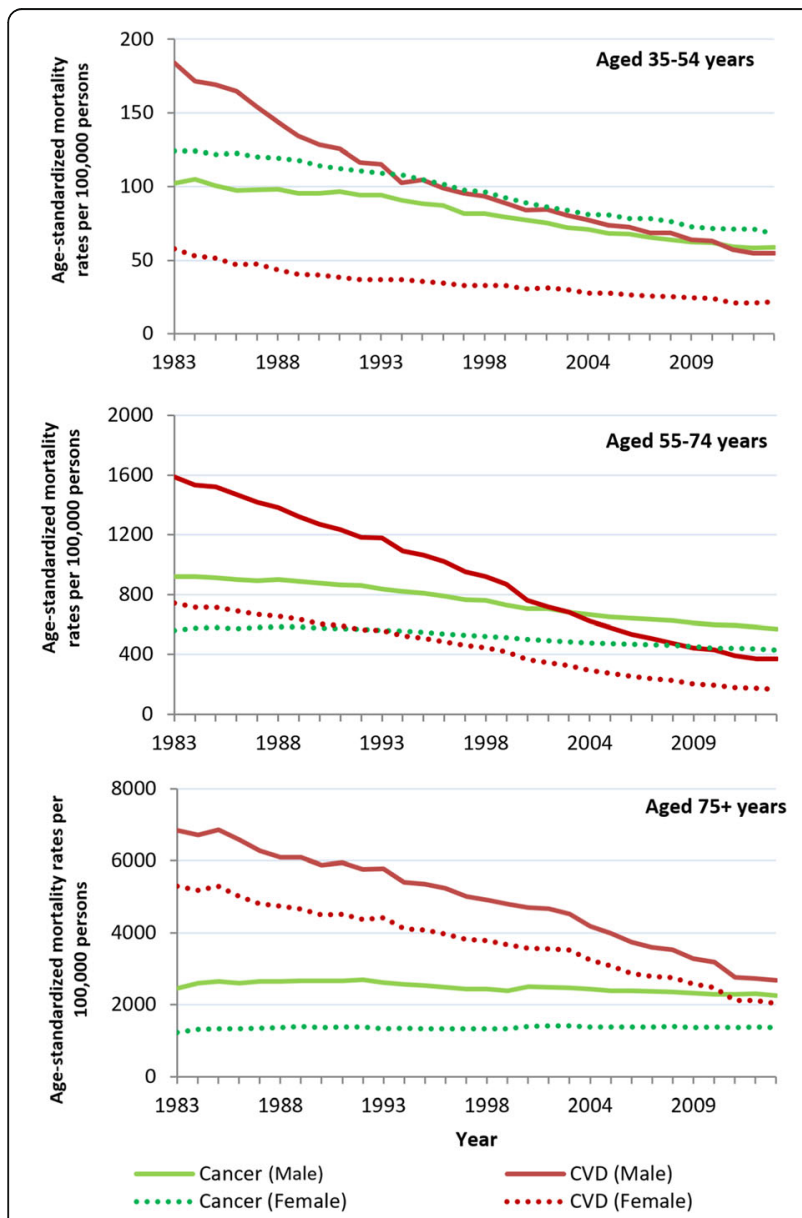

Fig. 3 Age-standardized mortality trends for cancer and CVD by age group and sex. Legend: Years 1983 to 2013. Note different scale axis and third periods. The steepest decrease for cancer was in the second period, while the first period showed no significant change in men and a small significant increase in women. From 1983 to 2013, CVD mortality had steeper decreases than cancer in all periods.

\section{Age group mortality trends}

In 2013, the absolute number of deaths from CVD and cancer increased with each age group for both sexes. For the study period, most age groups showed a significant decrease in age-standardized cancer and CVD mortality rates, except cancer in women aged $75+$, and CVD in men aged 15-34 years (Fig. 2). The widest sex difference in CVD mortality rate was in those aged 35-54 years. After this age group, sex differences in rate narrowed with increasing age. This pattern was not apparent for cancer, with men showing higher cancer rates than women for all age groups except those aged 35-54 years (Fig. 2).

Age-specific mortality rates showed cancer remained the most common cause of death among women less than 55 years of age and men less than 35 years. CVD remained the most common cause of death for men and women 75 years and older for the study period. Therefore the change from CVD to cancer as the primary cause of age-standardized mortality occurred in three groups: men aged 35-54 years in 2011, men aged 55-74 years in 2003, and women aged 55-74 years in 1992 (Fig. 3).

Joinpoint regression analysis showed the steepest decreases in age-specific cancer mortality rates for the study period were for men and women under 55 years (Table 3). No joinpoints were identified for cancer in men and women under 35 years. Cancer trends in age groups over 35 years were variable, with most showing a slowing in rate decrease in the most recent period. 


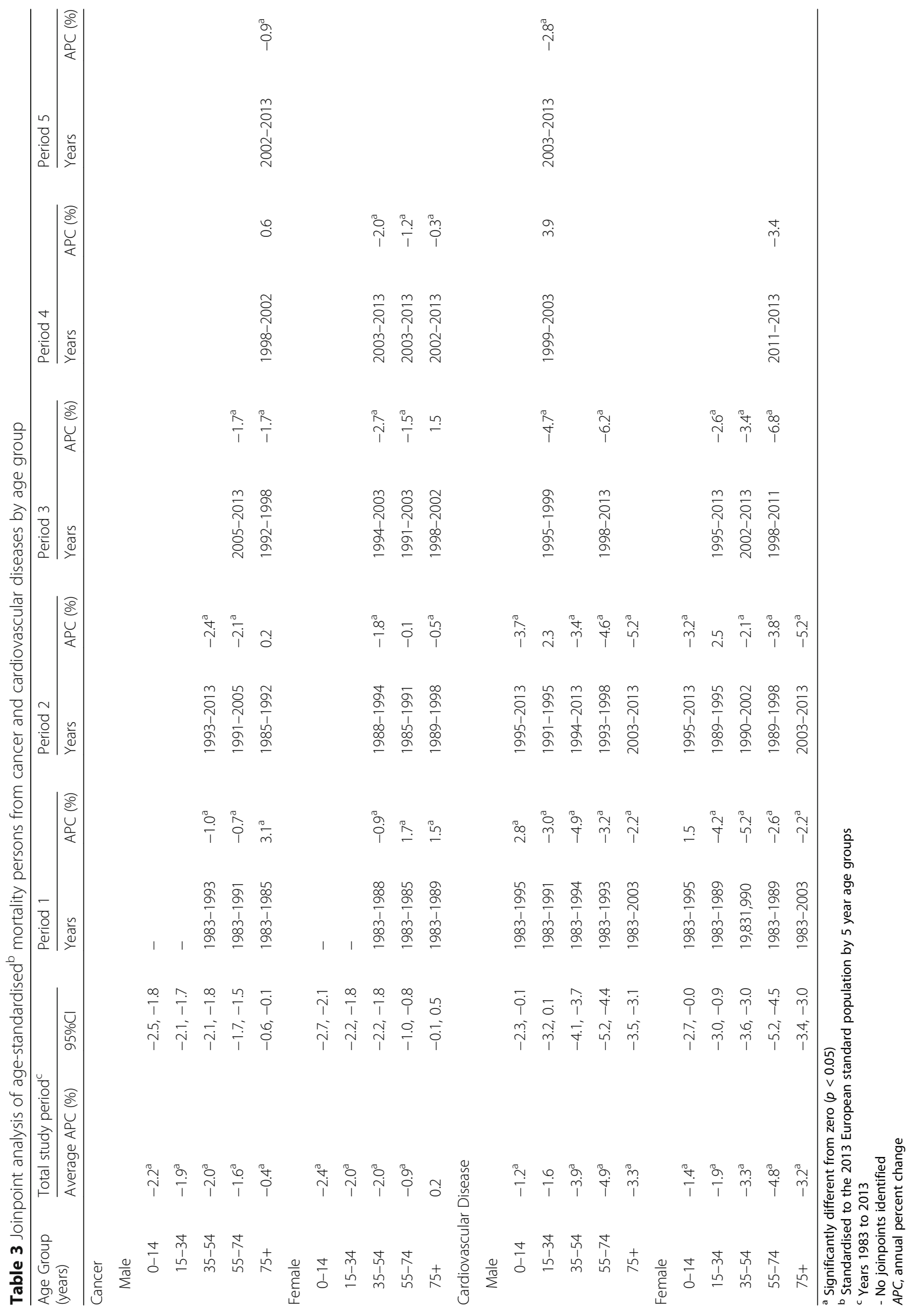



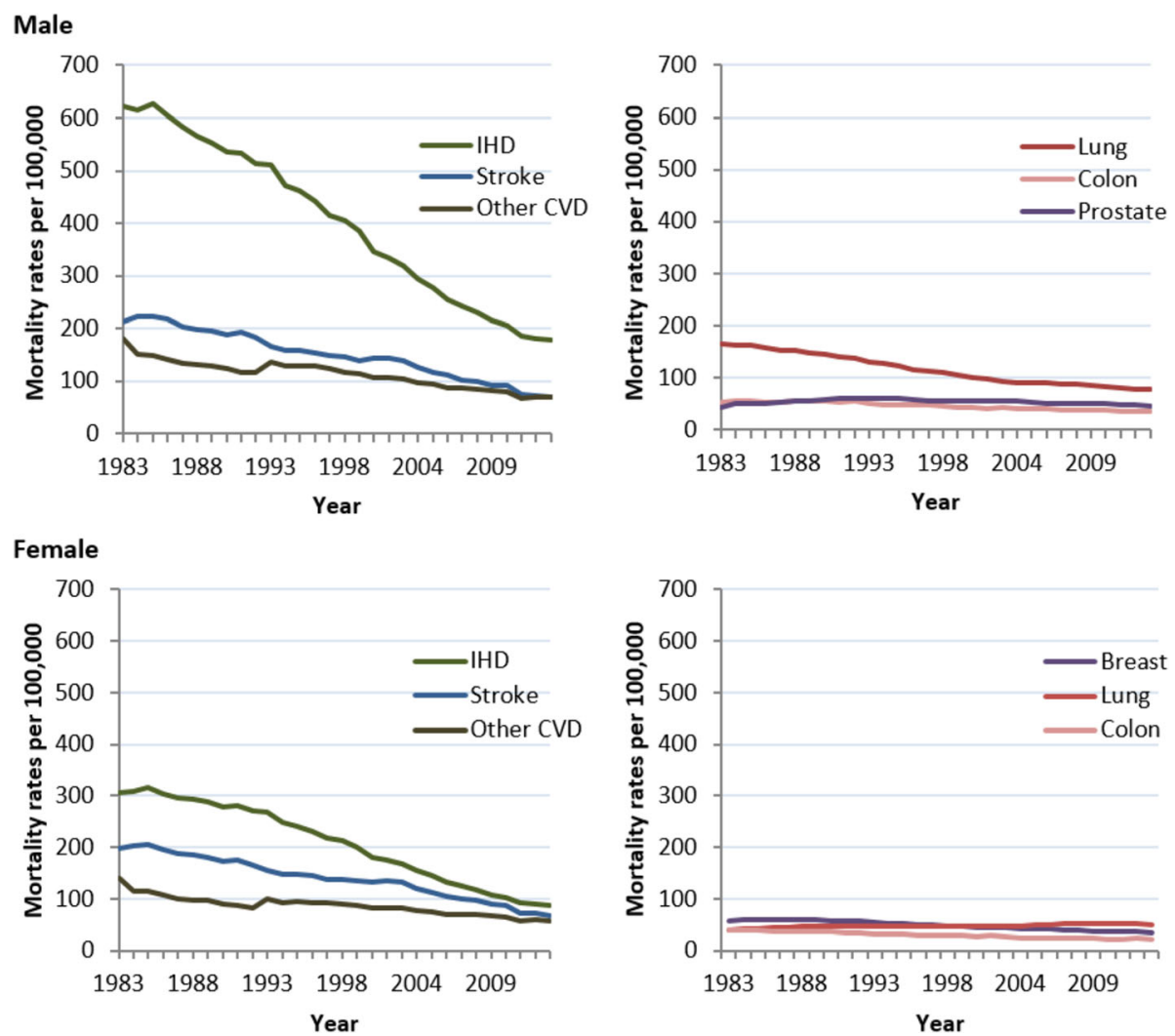

Fig. 4 Age-standardized mortality trends for IHD, stroke, other CVD, and lung, colon, breast, and prostate cancer. Legend: Years 1983 to 2013. IHD: ischemic heart disease

The steepest decreases in CVD mortality rate for the study period were for men and women aged 5574 years, followed by those aged $35-54$ years (Table $3)$. In men over 54 years, the decrease in agestandardized CVD mortality increased with each period identified. This was the same for women except for no significant change in the most recent period for women aged 55-74 years (years 20112013). In men and women aged 15-54 years, the steepest decreases were observed in the first period followed by non-significant periods or a slowing in rate. While in women of this age, the CVD mortality rate improved in the latest period, this has yet to occur for men of this age group.

\section{Disease type mortality trends}

The absolute number of deaths over the study period increased for prostate cancer, female lung cancer, and slightly for male colorectal cancer, while absolute deaths of all CVD types decreased. Of the types considered, IHD had the highest age-standardized mortality rate for CVDs (and overall mortality) for both sexes for the study period. Men and women had similar rates of stroke and other CVD but men had much higher rates of IHD. For cancer, the highest age- standardized mortality rate for both sexes was for lung cancer, although this trend occurred starting in 1998 for women (Fig. 4). Most disease types had significant decreases in age-standardized mortality from 1983 to 2013. The exceptions were female lung cancer, with a small significant increase, and prostate cancer, which had no significant change in overall mortality rate.

Joinpoint regression analysis showed that the steepest decreases in CVD type for the period were for IHD at a decrease of $4.1 \%$ per year for both sexes (Table 4). The decrease in age-standardized rate of IHD and stroke increased with each period identified for both sexes, except for a period with no significant change in IHD from 2011 to 2013. Other CVD saw its steepest decreases in the first period identified, followed by no significant change, and a slowing in rate in the most recent period.

Compared to CVD, trends in cancer mortality rates had fewer similarities between types, even between sexes, with a tendency toward fluctuating rates of mortality decrease and periods of non-significant change in rate. The largest overall decreases in cancer were for lung cancer in men and colorectal cancer in women. While male lung cancer was characterized by five 
Table 4 Joinpoint analysis of age-standardised mortality ${ }^{\mathrm{b}}$ rates by leading types of cancer and cardiovascular diseases

\begin{tabular}{|c|c|c|c|c|c|c|c|c|c|c|c|c|c|c|}
\hline & \multicolumn{2}{|c|}{$\begin{array}{l}\text { Mortality } \\
\text { per } 100,000\end{array}$} & \multicolumn{2}{|c|}{ Total study period ${ }^{c}$} & \multicolumn{2}{|c|}{ Period 1} & \multicolumn{2}{|c|}{ Period 2} & \multicolumn{2}{|c|}{ Period 3} & \multicolumn{2}{|c|}{ Period 4} & \multicolumn{2}{|l|}{ Period 5} \\
\hline & 1983 & 2013 & $\begin{array}{l}\text { Average APC } \\
(\%)\end{array}$ & $95 \% \mathrm{Cl}$ & Years & $\begin{array}{l}\text { APC } \\
(\%) \\
\end{array}$ & Years & $\begin{array}{l}\text { APC } \\
(\%)\end{array}$ & Years & $\begin{array}{l}\text { APC } \\
(\%)\end{array}$ & Years & $\begin{array}{l}\text { APC } \\
(\%) \\
\end{array}$ & Years & $\begin{array}{l}\text { APC } \\
(\%)\end{array}$ \\
\hline \multicolumn{15}{|l|}{ Cancer } \\
\hline \multicolumn{15}{|l|}{ Lung } \\
\hline Male & 165.7 & 77.2 & $-2.6^{\mathrm{a}}$ & $\begin{array}{l}-2.8 \\
-2.4\end{array}$ & $\begin{array}{l}1983- \\
1991\end{array}$ & $-2.0^{\mathrm{a}}$ & $\begin{array}{l}1991- \\
1997\end{array}$ & $-3.8^{\mathrm{a}}$ & $\begin{array}{l}1997- \\
2004\end{array}$ & $-2.9^{a}$ & $\begin{array}{l}2004- \\
2008\end{array}$ & $-1.1^{\mathrm{a}}$ & 2008-2013 & $-2.5^{\mathrm{a}}$ \\
\hline Female & 39.9 & 50.7 & $0.7^{\mathrm{a}}$ & $0.5,1.0$ & $\begin{array}{l}1983- \\
1989\end{array}$ & $2.4^{\mathrm{a}}$ & $\begin{array}{l}1989- \\
2004\end{array}$ & 0.1 & $\begin{array}{l}2004- \\
2008\end{array}$ & $2.1^{\mathrm{a}}$ & $\begin{array}{l}2008- \\
2013\end{array}$ & -0.5 & & \\
\hline \multicolumn{15}{|l|}{ Colorectal } \\
\hline Male & 54.0 & 35.3 & $-1.5^{\mathrm{a}}$ & $\begin{array}{l}-1.9 \\
-1.0\end{array}$ & $\begin{array}{l}1983- \\
1992\end{array}$ & -0.3 & $\begin{array}{l}1992- \\
1995\end{array}$ & -3.7 & $\begin{array}{l}1995- \\
2013\end{array}$ & $-1.6^{\mathrm{a}}$ & & & & \\
\hline Female & 38.9 & 22.8 & $-2.1^{\mathrm{a}}$ & $\begin{array}{l}-2.2 \\
-1.9\end{array}$ & $\begin{array}{l}1983- \\
2013\end{array}$ & $-2.1^{\mathrm{a}}$ & & & & & & & & \\
\hline \multicolumn{15}{|l|}{ Prostate } \\
\hline Male & 43.7 & 46.8 & 0.1 & $\begin{array}{l}-0.1 \\
0.3\end{array}$ & $\begin{array}{l}1983- \\
1992\end{array}$ & $3.0^{\mathrm{a}}$ & $\begin{array}{l}1992- \\
2013\end{array}$ & $-1.2^{\mathrm{a}}$ & & & & & & \\
\hline \multicolumn{15}{|l|}{ Breast } \\
\hline Female & 56.2 & 35.5 & $-1.5^{\mathrm{a}}$ & $\begin{array}{l}-1.8 \\
-1.2\end{array}$ & $\begin{array}{l}1983- \\
1985\end{array}$ & 2.6 & $\begin{array}{l}1985- \\
1991\end{array}$ & -0.4 & $\begin{array}{l}1991- \\
1998\end{array}$ & $-2.9^{a}$ & $\begin{array}{l}1998- \\
2002\end{array}$ & -1.3 & 2002-2013 & $-2.1^{a}$ \\
\hline \multicolumn{15}{|c|}{ Cardiovascular Diseases } \\
\hline \multicolumn{15}{|c|}{ Ischaemic Heart Disease } \\
\hline Male & 622.1 & 177.2 & $-4.1^{a}$ & $\begin{array}{l}-4.5 \\
-3.7\end{array}$ & $\begin{array}{l}1983- \\
1985\end{array}$ & -0.2 & $\begin{array}{l}1985- \\
1993\end{array}$ & $-2.5^{\mathrm{a}}$ & $\begin{array}{l}1993- \\
2002\end{array}$ & $-4.4^{a}$ & $\begin{array}{l}2002- \\
2011\end{array}$ & $-6.2^{\mathrm{a}}$ & $2011-2013$ & -3.3 \\
\hline Female & 306.2 & 86.5 & $-4.1^{\mathrm{a}}$ & $\begin{array}{l}-4.5 \\
-3.8\end{array}$ & $\begin{array}{l}1983- \\
1985\end{array}$ & 1.0 & $\begin{array}{l}1985- \\
1993\end{array}$ & $-2.0^{\mathrm{a}}$ & $\begin{array}{l}1993- \\
2003\end{array}$ & $-4.5^{\mathrm{a}}$ & $\begin{array}{l}2003- \\
2011\end{array}$ & $-7.0^{\mathrm{a}}$ & 2011-2013 & -3.8 \\
\hline \multicolumn{15}{|l|}{ Stroke } \\
\hline Male & 213.4 & 70.0 & $-3.7^{\mathrm{a}}$ & $\begin{array}{l}-4.5 \\
-2.9\end{array}$ & $\begin{array}{l}1983- \\
1985\end{array}$ & 2.0 & $\begin{array}{l}1985- \\
1998\end{array}$ & $-3.4^{a}$ & $\begin{array}{l}1998- \\
2002\end{array}$ & 0.3 & $\begin{array}{l}2002- \\
2013\end{array}$ & $-6.5^{\mathrm{a}}$ & & \\
\hline Female & 199.1 & 67.9 & $-3.5^{a}$ & $\begin{array}{l}-4.1 \\
-3.0\end{array}$ & $\begin{array}{l}1983- \\
1985\end{array}$ & 1.1 & $\begin{array}{l}1985- \\
1997\end{array}$ & $-3.2^{\mathrm{a}}$ & $\begin{array}{l}1997- \\
2003\end{array}$ & -1.0 & $\begin{array}{l}2003- \\
2013\end{array}$ & $-6.3^{a}$ & & \\
\hline \multicolumn{15}{|l|}{ Other CVD } \\
\hline Male & 180.2 & 69.0 & $-2.9^{\mathrm{a}}$ & $\begin{array}{l}-3.7 \\
-2.1\end{array}$ & $\begin{array}{l}1983- \\
1991\end{array}$ & $-4.4^{a}$ & $\begin{array}{l}1991- \\
1995\end{array}$ & 3.6 & $\begin{array}{l}1995- \\
2013\end{array}$ & $-3.6^{a}$ & & & & \\
\hline Female & 140.0 & 58.1 & $-2.6^{\mathrm{a}}$ & $\begin{array}{l}-3.5 \\
-1.7\end{array}$ & $\begin{array}{l}1983- \\
1991\end{array}$ & $-5.2^{\mathrm{a}}$ & $\begin{array}{l}1991- \\
1995\end{array}$ & 3.8 & $\begin{array}{l}1995- \\
2013\end{array}$ & $-2.8^{\mathrm{a}}$ & & & & \\
\hline
\end{tabular}

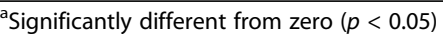

${ }^{\text {b }}$ Standardised to the 2013 European standard population by 5-year age groups

c Years 1983 to 2013

$A P C$, annual percent change

periods of decreasing mortality at variable rates, female lung cancer showed no periods of decrease.

\section{Discussion}

The results of this study support the evidence for decreasing mortality rates of CVD $[2,12]$ and cancer [13] in the UK, expanding the analysis over 30 years with a comparison of the two diseases. Mortality rates were higher for CVD than cancer for most of the study period, with a change to cancer having the higher age-standardized mortality rate for both sexes in 2011. There was a narrowing of the difference in mortality between CVD and cancer by most sex, age, and disease-type groups. This appears to be because of a steeper decrease in mortality from CVD and a slowing in the decrease of cancer since 1997.

The decrease in CVD and cancer mortality observed in the UK has been seen in most other countries of Western Europe. This includes a small decrease of the most common cancers [4, 14], increasing female lung cancer [4], and a larger decrease in CVD mortality $[3,15]$. The change from CVD to cancer as the more common cause of age-standardized mortality in both sexes has occurred in Denmark, France, Israel, 
and the Netherlands, and in Belgium, Portugal, and Spain for males only [5]. Further analysis is required to determine if the underlying trends as observed in this study are occurring in other European countries.

Mortality rates have decreased for CVD due to improvements in risk factors and progress in diagnosis and medical treatment, including acute hospital cases [16-19]. For example, uptake of treatments, such as statins and hypertensive medicines, was attributed to half of the decrease in IHD mortality between 2000 to 2007 in England [16, 20]. Modest decreases in colon, breast, and prostate cancer were attributed to advances in treatment and earlier diagnosis $[13,21]$. The effectiveness of screening is debated due to lag times [22]. For example, the outcomes of introducing bowel cancer screening in the UK in 2006 are unclear [23]. In the UK, the decrease in smoking attribution to cancer in men is far larger than in women, likely due to the delayed habit uptake from women in the 1940s [24].

The Global Burden of Disease 2015 suggests only $47 \%$ of cancer mortality rates were related to modifiable risk factors compared to $80 \%$ of CVD mortality rates in the UK [25]. Although cancer and CVD share many risk factors, a change in risk prevalence does not contribute to an equal change in cancer and CVD mortality over time. For example, the overall prevalence of smoking has decreased over 25 years, but the improvement in smoking-attributed mortality rate has been greater for CVD than cancer. This is likely due to the shorter lag effect from smoking exposure to disease for CVD. To assess the etiology of the trends determined in this paper, further research will need to consider the differing effects of risk factors on cancer and CVD over time.

Assuming current trends in risk reduction, modeling studies predict IHD death rates to continue declining in the UK [26]. Yet high body mass index (BMI) is a risk factor for CVD [27] and some cancers [28]. In England, the prevalence of obesity and associated diabetes is increasing, particularly in young women and those already with a high BMI $[29,30]$. A study of English diabetics suggested there had been little decrease in IHD mortality in this group between 1995 and 2010 [31]. Previous reports from England and the US suggest a slowing in the decrease of CVD mortality in those aged 3554 years during the 1990s with links to rising obesity $[6,32]$. Our study suggested decreases in CVD mortality have steepened in women of this age in the last decade, a trend also observed in the Netherlands [33], but so far not in men. Continuing to monitor trends is essential to understand the effect of these interactions on public health.

\section{Limitations}

The UK mortality data derived from the WHO database are considered to be of high quality due to high death registration coverage of its constituent countries and low levels of ICD miscoding [34]. Coding rules are in place to ensure that the correct underlying cause of death is selected with the majority of deaths coded automatically with software. However, mortality from CVD can be difficult to assess by death certificates [35]. For those over the age of 75 years, there is a higher chance of coexisting conditions with CVD, particularly in cancer survivors [36], increasing the difficulty of determining a single cause of death. One study in England found that considering only the underlying cause of death resulted in missing around a quarter of all stroke deaths between 1979 and 2004 [37]. Coding revision from ICD-9 to ICD-10 was known to affect records of stroke and other CVD in the 1980s to 1990 s by a temporary use of only the underlying cause of death on certificates [38]. In addition, ICD coding reassignment caused some disease categories to increase in number of deaths, including a $2.3 \%$ increase in numbers of malignant neoplasms [39] and a 3\%-4\% increase in circulatory diseases [38]. Therefore, the results from the initial period of our study period may show unintended variation. The low number of cases at younger ages can create a less reliable agestandardized rate.

\section{Conclusions}

The UK saw a narrowing in age-standardized mortality rates from CVD and cancer for both sexes between 1983 and 2013. Both diseases significantly decreased overall except for female lung cancer, which significantly increased during this period. Rates of decrease have slowed for cancer in both sexes.

\section{Abbreviations}

AAPC: Average annual percentage change; APC: Annual percentage change; ASMR: Age-standardised mortality rate; BMI: Body mass index; CVD: Cardiovascular disease; ESP: European standard population; ICD: International classification of diseases; IHD: Ischemic heart disease

\section{Funding}

All authors were funded by the British Heart Foundation (grant URN =006/P\&C) CORE/2013/OXFSTATS). No funding was received specifically for this work.

\section{Availability of data and materials}

The dataset supporting the conclusions of this article is available in the WHO Mortality database, http://www.who.int/healthinfo/mortality_data/en/.

\section{Authors'contributions}

LW carried out the analyses, drafted the paper, and finalized the paper based on comments from co-authors. PB and NT had the original idea and commented on drafts of the paper. All authors approved the final version of the paper.

Ethics approval and consent to participate Not applicable.

Consent for publication

Not applicable.

Competing interests

The authors declare that they have no competing interests. 


\section{Publisher's Note}

Springer Nature remains neutral with regard to jurisdictional claims in published maps and institutional affiliations.

Received: 28 July 2016 Accepted: 25 June 2017

Published online: 01 July 2017

\section{References}

1. GBD 2013 Mortality and Causes of Death Collaborators. Global, regional, and national age-sex specific all-cause and cause-specific mortality for 240 causes of death, 1990-2013: a systematic analysis for the global burden of disease study 2013. Lancet. 2015;385(9963):117-71.

2. Bhatnagar $P$, Wickramasinghe $K$, Williams J, Rayner M, Townsend N. The epidemiology of cardiovascular disease in the UK 2014. Heart. 2015; doi:10. 1136/heartjnl-2015-307516.

3. Nichols M, Townsend N, Scarborough P, Rayner M. Trends in age-specific coronary heart disease mortality in the European Union over three decades: 1980-2009. Eur Heart J. 2013;34(39):3017-27. doi:10.1093/eurheartj/eht159.

4. Bosetti C, Bertuccio P, Malvezzi M, Levi F, Chatenoud L, Negri E, et al. Cancer mortality in Europe, 2005-2009, and an overview of trends since 1980. Ann Oncol. 2013;24(10):2657-71. doi:10.1093/annonc/mdt301.

5. Townsend N, Nichols M, Scarborough P, Rayner M. Cardiovascular disease in Europe-epidemiological update 2015. Eur Heart J. 2015;36(40):2673-4. doi: 10.1093/eurheartj/ehv428.

6. O'Flaherty M, Ford E, Allender S, Scarborough P, Capewell S. Coronary heart disease trends in England and Wales from 1984 to 2004: concealed levelling of mortality rates among young adults. Heart. 2008;94(2):178-81.

7. Pereira M, Peleteiro B, Capewell S, Bennett K, Azevedo A, Lunet N. Changing patterns of cardiovascular diseases and cancer mortality in Portugal, 19802010. BMC Public Health. 12:2012, 1126

8. Lim SS, Vos T, Flaxman AD, Danaei G, Shibuya K, Adair-Rohani H, et al. A comparative risk assessment of burden of disease and injury attributable to 67 risk factors and risk factor clusters in 21 regions, 1990-2010: a systematic analysis for the global burden of disease study 2010. Lancet. 380(9859):2013, 2224-60.

9. Griffiths C, Rooney C, Brock A. Leading causes of death in England and Wales-how should we group causes. Health Stat Q. 2005;28:6-17.

10. Mathers CD, Bernard C, Iburg KM, Inoue M, Ma Fat D, Shibuya K, et al. Global burden of disease in 2002: data sources, methods and results. World Health Organization; 2003. http://www.who.int/healthinfo/paper54.pdf

11. Townsend N, Bhatnagar P, Wilkins E, Wickramasinghe K, Rayner M. Cardiovascular disease statistics, 2015. London: British Heart Foundation; 2015.

12. Davies AR, Smeeth L, Grundy EM. Contribution of changes in incidence and mortality to trends in the prevalence of coronary heart disease in the UK: 1996 2005. Eur Heart J. 28(17):2007, 2142-7.

13. Marshall DC, Webb TE, Hall RA, Salciccioli JD, Ali R, Maruthappu M. Trends in UK regional cancer mortality 1991-2007. Br J Cancer. 114(3):2016, 340-7.

14. Bray F, Jemal A, Grey N, Ferlay J, Forman D. Global cancer transitions according to the human development index (2008-2030): a populationbased study. Lancet Oncol. 2012;13(8):790-801.

15. Feigin VL, Forouzanfar MH, Krishnamurthi R, Mensah GA, Connor M, Bennett DA, Moran AE, Sacco RL, Anderson L, Truelsen T, O'Donnell M, Venketasubramanian N, Barker-Collo S, Lawes CMM, Wang M, Shinohara Y, Witt E, Ezzati M, Naghavi M, Murray C. Global and regional burden of stroke during 1990? 2010: findings from the Global Burden of Disease Study 2010. The Lancet. 2010;383(9913):245-55.

16. Smolina K, Wright FL, Rayner M, Goldacre MJ. Determinants of the decline in mortality from acute myocardial infarction in England between 2002 and 2010: linked national database study. BMJ. 2012;doi:10.1136/bmj.d8059.

17. Unal B, Critchley JA, Capewell S. Explaining the decline in coronary heart disease mortality in England and Wales between 1981 and 2000. Circulation. 2004; doi:10.1161/01.CIR.0000118498.35499.B2.

18. Unal B, Critchley JA, Capewell S. Modelling the decline in coronary heart disease deaths in England and Wales, 1981-2000: comparing contributions from primary prevention and secondary prevention. BMJ. 2005;331(7517):614.

19. Hardoon SL, Whincup PH, Lennon LT, Wannamethee SG, Capewell S, Morris RW. How much of the recent decline in the incidence of myocardia infarction in British men can be explained by changes in cardiovascular risk factors? Evidence from a prospective population-based study. Circulation. 2008; doi:10.1161/CIRCULATIONAHA.107.705947.
20. Bajekal M, Scholes S, Love H, Hawkins N, O'flaherty M, Raine R, et al. Analysing recent socioeconomic trends in coronary heart disease mortality in England, 2000-2007: a population modelling study. PLoS Med. 2012;(6):9, e1001237.

21. Jatoi I, Miller AB. Why is breast-cancer mortality declining? Lancet Oncol. 2003:4(4):251-4

22. Lee SJ, Boscardin WJ, Stijacic-Cenzer I, Conell-Price J, O'Brien S, Walter LC. Time lag to benefit after screening for breast and colorectal cancer: metaanalysis of survival data from the United States, Sweden, United Kingdom, and Denmark. BMJ. 2013;doi:10.1136/bmj.e8441.

23. Logan RF, Patnick J, Nickerson C, Coleman L, Rutter MD, von Wagner C, et al. Outcomes of the bowel cancer screening Programme (BCSP) in England after the first 1 million tests. Gut. 2012;61(10):1439-46.

24. Pirie K, Peto R, Reeves GK, Green J, Beral V. The 21 st century hazards of smoking and benefits of stopping: a prospective study of one million women in the UK. The Lancet. 2013;381(9861):133-41.

25. Institute for Health Metrics and Evaluation (IHME). Global Burden of Disease Results Tool. University of Washington. 2016

26. Kontis V, Mathers CD, Rehm J, Stevens GA, Shield KD, Bonita R, et al. Contribution of six risk factors to achieving the $25 \times 25$ non-communicable disease mortality reduction target: a modelling study. 2014

27. Global Burden of Metabolic Risk Factors for Chronic Diseases Collaboration (BM Mediated Effects), Lu Y, Hajifathalian K, Ezzati M, Woodward M, Rimm E, et al. Metabolic mediators of the effects of body-mass index, overweight, and obesity on coronary heart disease and stroke: a pooled analysis of 97 prospective cohorts with 1.8 million participants. Lancet. 2014;383(9921):970-83.

28. Bhaskaran K, Douglas I, Forbes H, dos-Santos-Silva I, Leon DA, Smeeth L. Body-mass index and risk of 22 specific cancers: a population-based cohort study of 5. 24 million UK adults. Lancet. 2014;384(9945):755-65.

29. Sperrin M, Marshall A, Higgins V, Buchan I, Renehan AG. Slowing down of adult body mass index trend increases in England: a latent class analysis of cross-sectional surveys (1992-2010). Int J Obes. 38(6):2014, 818-24.

30. Green M, Subramanian S, Razak F. Population-level trends in the distribution of body mass index in England, 1992-2013. J Epidemiol Community Health. 70(8):2016, 832-5.

31. Ecclestone T, Yeates D, Goldacre M. Fall in population-based mortality from coronary heart disease negated in people with diabetes mellitus: data from England. Diabetic Med. 2015;32(10):1329-34.

32. Wilmot KA, O'Flaherty M, Capewell S, Ford ES, Vaccarino V. Coronary Heart Disease Mortality Declines in the United States From 1979 Through 2011: Evidence for Stagnation in Young Adults, Especially Women. Circulation. 2015: doi:10.1161/CIRCULATIONAHA 115.015293.

33. Vaartjes I, O'Flaherty M, Grobbee DE, Bots ML, Capewell S. Coronary heart disease mortality trends in the Netherlands 1972-2007. Heart. 2011; doi:10. 1136/hrt.2010.206565.

34. World Health Organization. WHO Methods and Data Sources for Countrylevel Causes of Death 2000-2012. Global Health Estimates Technical Paper. 2014:WHO/HIS/HSI/GHE/2014.7.

35. Pagidipati NJ, Gaziano TA. Estimating deaths from cardiovascular disease: a review of global methodologies of mortality measurement. Circulation. 2013; doi:10.1161/CIRCULATIONAHA.112.128413.

36. Patnaik JL, Byers T, DiGuiseppi C, Dabelea D, Denberg TD. Cardiovascular disease competes with breast cancer as the leading cause of death for older females diagnosed with breast cancer: a retrospective cohort study. Breast Cancer Res. 2011:(3):13, R64.

37. Goldacre MJ, Duncan M, Griffith M, Rothwell PM. Mortality rates for stroke in England from 1979 to 2004: trends, diagnostic precision, and artifacts. Stroke. 2008; doi:10.1161/STROKEAHA.107.509695 [doi].

38. Griffiths C, Brock A, Rooney C. The impact of introducing ICD-10 on trends in mortality from circulatory diseases in England and Wales. Health Stat Q. 2004:22:14-20

39. Brock A, Griffiths C, Rooney C. The effect of the introduction of ICD-10 on cancer mortality trends in England and Wales. Health Stat Q. 2004. 